\title{
Fotohistoria: modelo de innovación docente a través de la fotografía
}

Photo-History: a model for teaching innovation using photographies

\author{
María Olivera Zaldua (1), Juan Miguel Sánchez Vigil (2), Juan Carlos Marcos Recio (3)
}

(1) Departamento de Biblioteconomía y Documentación, Facultad de Ciencias de la Documentación UCM, C/Santísima Trinidad 37, 28010 Madrid, molivera@ucm.es. (2) jmvigil@ucm.es (3) Sección Departamental de Biblioteconomía y Documentación, Facultad de Ciencias de la Información UCM, Av. Ciudad Universitaria s/n. 28040, jmarcos@ucm.es

\begin{abstract}
Resumen
Las experiencias docentes con la fotografía son relativamente escasas a pesar de los excelentes resultados de sus aplicaciones en la docencia. Se presenta el proyecto y los resultados de un modelo desarrollado en la Facultad de Ciencias de la Documentación de la Universidad Complutense con el título Fotohistoria, cuyo objetivo primero es fomentar la participación y formación de los estudiantes, y al mismo tiempo crear una fototeca histórica de alta calidad, de contenidos diversos, documentos únicos e inéditos dispuestos para su uso no comercial y libres de derechos. Fruto de esta experiencia es un banco de imágenes histórico compuesto por más de setecientas imágenes, procedentes de las colecciones particulares de 244 alumnos y fechadas entre 1880 y 1975.
\end{abstract}

Palabras clave: Innovación docente. Metodología docente. Bancos de imágenes. Documentación fotográfica. Fototecas históricas. Fotografía.

\section{Introducción}

La innovación docente es uno de los objetivos prioritarios de todas las universidades. Los profesionales necesitan ideas y herramientas que les ayuden a alcanzar las metas propuestas en relación a la consecución de las aptitudes, habilidades y competencias necesarias para responder a la demanda. En anteriores trabajos sobre esta materia, relacionados con el proyecto Imaginando (Sánchez Vigil, 2012; Sánchez Vigil, Marcos Recio, Olivera Zaldua, 2014b), ya se ha señalado la importancia del uso de la imagen en la docencia y la respuesta positiva de los estudiantes cuando se convierten en protagonistas del proceso.

El valor de la fotografía es incuestionable, y su uso y aplicación en la docencia un hecho, si bien es mínima su presencia en los planes de estudio, tanto en la enseñanza secundaria como en la superior. Por ello, se diseñó el proyecto Fotohistoria como una herramienta metodológica para despertar el interés de los estudiantes. La idea se basa en la recuperación de las fotografías de las colecciones particulares, cuyo

\begin{abstract}
Very few teaching experiences with Photography exist despite the excellent results obtained from its application to education. A model is presented that was developed by the Faculty of Information Sciences of the Universidad Complutense of Madrid, under the title "Fotohistoria". Its main goals are to promote student participation and training; and at the same time create an important historical phototheque, of diverse contents and out-standing and hitherto unpublished documents, which are made available for non-commercial use and free of rights. The end result of this experience is a historical image bank made up of seven hundred photographs coming from the private collections of 244 students, and dated between 1880 and 1975.
\end{abstract}

Keywords: Innovative teaching. Teaching methodologly. Image banks. Photographic documentation. Historic phototheques. Photography.

contenido pueda formar parte de una fototeca histórica, que actualmente es de uso abierto para los estudiantes, profesores e investigadores, y con ubicación en la Facultad de Ciencias de la Documentación de la Universidad Complutense.

El uso de la fotografía en la docencia tiene numerosas experiencias en campos diversos: la lengua inglesa (Britsch, 2010), las matemáticas (Munakata y Vaidya, 2012) o la documentación (Springborg, 2013). En España, el principal campo donde la fotografía cumplió y cumple una tarea específica es el del arte, con trabajos sobre colecciones históricas como la de los profesores Enrique Lafuente Ferrari, cuyo fondo se conserva en la biblioteca Valdecilla de la Universidad Complutense de Madrid (Casajús; Diéguez; Pena, 2008), y Diego Angulo Íñiguez (Rincón, 2012), en la biblioteca Tomás Navarro Tomás del Consejo Superior de Investigaciones Científicas. Sobre la aplicación de la fotografia a la docencia en la Universidad los textos se centran en su uso específico, de acuerdo a planteamientos concretos (Moreiro, 2014), pero no se han localizado trabajos exhaustivos o tesis 
doctorales (Sánchez Vigil, Marcos Recio, Olivera Zaldua, 2014a).

Los modelos que se han seguido para la creación de bancos de imágenes de las características que presentamos se encuentran en las Comunidades Autónomas, si bien estos proyectos son abiertos con el objetivo general de recuperar imágenes de ciudades, pueblos y paisajes, así como de tipos y costumbres. El ejemplo más ilustrativo es el trabajo del Archivo Fotográfico de la Comunidad de Madrid, cuyo contenido son imágenes recuperadas de los archivos personales, y en el que se han reunido miles de documentos (Sánchez Vigil, Salvador Benítez, 2013).

El objeto de este artículo es mostrar los resultados del modelo metodológico de innovación docente con el que se ha conseguido la participación de los alumnos en los procesos de enseñanza y en la investigación. Siguiendo las pautas del Espacio Europeo de Educación Superior (López del Ramo, 2008) se pretendió la motivación de los estudiantes para conseguir su activa participación, y al mismo tiempo se ha construido un banco de imágenes de alta calidad, dispuesto para su uso. En tres años de actuación se han cumplido ambos objetivos, con la participación de 244 estudiantes que ha dado como resultado una fototeca compuesta por más de 700 imágenes.

\section{Planteamiento metodológico}

El punto de referencia en la metodología propuesta es el estudiante, protagonista de princi- pio a fin, ya que toda la metodología gira en torno a su actividad. Partiendo del propósito de construir una fototeca histórica, con documentos inéditos de colecciones particulares, se establecieron cinco fases con criterios específicos de trabajo.

1. Fase primera: búsqueda y selección de las fotografias en el fondo personal; valoración de los documentos propios.

2. Fase segunda: valoración técnica, reproducción o escaneado; tratamiento con el software adecuado para obtener la máxima calidad.

3. Fase tercera: análisis documental de la fotografía; recuperación de toda la información relacionada con la imagen, tanto en continente como en contenido.

4. Fase cuarta: el banco de imágenes (estructura y materias); diseño del banco de imágenes; asignación de una materia específica a cada una de las fotografías seleccionadas.

5. Fase quinta: difusión de contenidos; diseño de las muestras o exposiciones para hacer públicos los documentos.

La aplicación de las cinco fases en el aula se desarrolló de manera progresiva, también en cinco escalas, en las que dos, la participación fue individual, y en tres colectiva o de grupo. Todas las actividades prácticas se contextualizaron con charlas teóricas sobre los temas propuestos, es decir, que se teorizó sobre cada materia, se explicó el sentido de cada propuesta y se consideraron los resultados de su aplicación.

\begin{tabular}{llll}
\hline Fase & Criterios de selección & Contextualización & Desarrollo \\
\hline 1 & $\begin{array}{l}\text { Fechas de referencia de las fotografías } \\
\text { y temáticas }\end{array}$ & $\begin{array}{l}\text { Los álbumes de fotografías. Contenidos, } \\
\text { aspectos técnicos }\end{array}$ & personal / individual \\
\hline 2 & $\begin{array}{l}\text { Estado de la fotografía (bueno, regular, } \\
\text { malo) }\end{array}$ & $\begin{array}{l}\text { Aspectos técnicos. Formatos de } \\
\text { archivos: jpg, tiff }\end{array}$ & personal / individual \\
\hline 3 & $\begin{array}{l}\text { Criterios para el análisis documental: } \\
\text { ficha de trabajo }\end{array}$ & $\begin{array}{l}\text { El análisis documental: recuperación y } \\
\text { reutilización }\end{array}$ & colectivo / grupo \\
\hline 4 & Tesauro & Fototecas: Titularidad y tipología & colectivo / grupo \\
\hline 5 & $\begin{array}{l}\text { Criterios para la difusión: exposición en } \\
\text { línea o física }\end{array}$ & $\begin{array}{l}\text { La difusión de contenidos: montaje de } \\
\text { una exposición }\end{array}$ & colectivo / grupo \\
\hline
\end{tabular}

Tabla I. Aplicación de las cinco fases en el aula

\section{Análisis documental}

En lo que se refiere al análisis documental de las fotografías, la metodología aplicada sigue los planteamientos de Marzal (2008), Heras (2012) y Sánchez Vigil, Salvador Benítez (2013), a partir de los cuales se elaboró una ficha de trabajo con campos sobre contenido y continente, de manera que se han considerado forma y fondo. La finalidad primera del análisis es la recuperación del fondo, de ahí la importancia del campo dedicado a los descriptores.

Se establecieron catorce campos para obtener información general de la fotografía (positivo en 
papel original) y datos técnicos del fichero digital generado tras la reproducción:

1. $N^{\circ}$ Identificador: número currens

2. Autor: apellidos y nombre del autor de la fotografía

3. Título: elegido por el propietario

4. Fecha: fecha de toma de la fotografía

5. Lugar: lugar en que se realizó la fotografía

6. Resumen: resumen del contenido

7. Descriptores onomásticos: nombres de personas físicas y jurídicas
8. Descriptores geográficos: nombres de lugares, accidentes geográficos, etc.

9. Descriptores cronológicos: fechas

10.Descriptores temáticos: connotativos y denotativos

11.Blanco y negro, o color

12.Formato: medidas de la fotografía original (cm.)

13. Fichero digital: características (dpi)

14.Observaciones: datos añadidos en la foto original (textos, estado, etc.)

En la Figura I se presenta un ejemplo de ficha.

FOTOHISTORIA

PROYECTO DE INNOVACIÓN DOCENTE

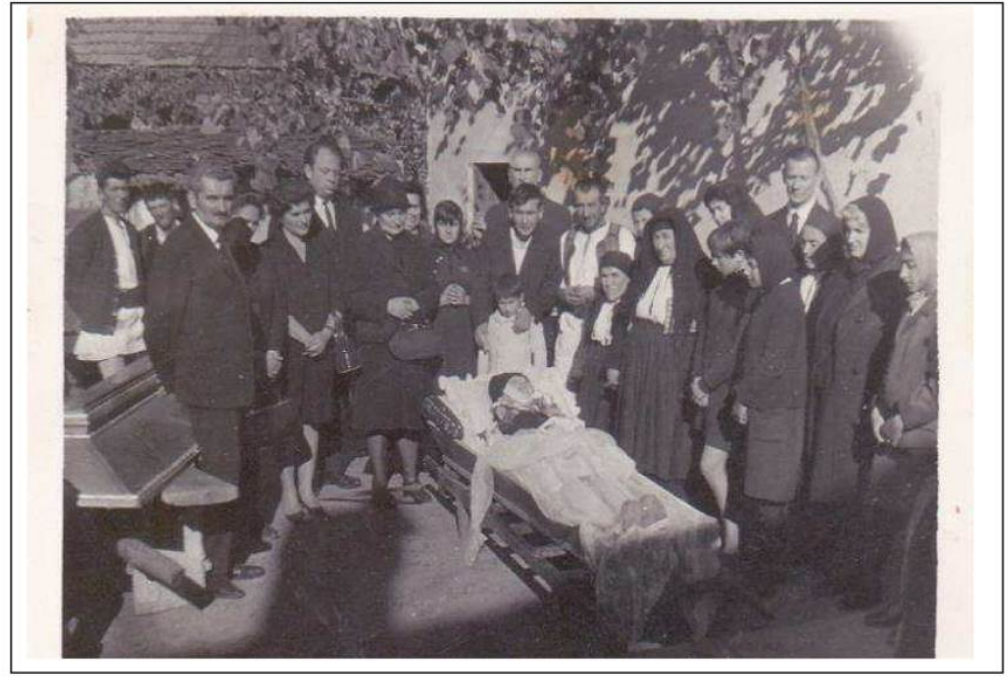

Identificado

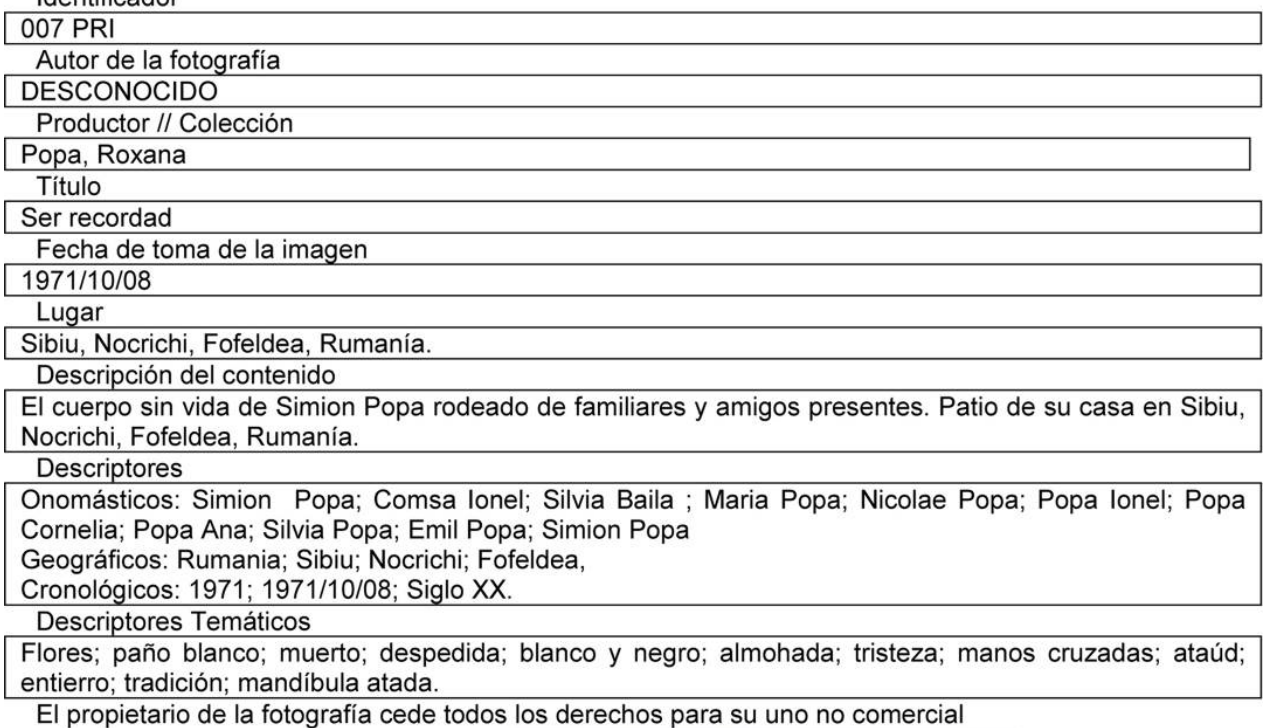

El propietario de la fotografía cede todos los derechos para su uno no comercial

FIRMADO

Figura 1. Ficha vaciado de las imágenes 


\section{Resultados}

El proyecto de innovación docente Fotohistoria de la Facultad de Ciencias de la Documentación se ha aplicado en dos asignaturas: Documentación Fotográfica y Documentación Informativa. El periodo de trabajo ha sido de tres cursos entre los años 2012-2015, es decir durante tres cursos consecutivos. El proceso efectivo, bajo el control de los responsables, se desarrolló en cuatro fases generales, desde la selección a la difusión:

1. Recopilación de las fotografías: selección

2. Reproducción: fotografiado o digitalización

3. Análisis documental: tratamiento en fondo y forma
4. Difusión: exposición o muestra de las reproducciones

Durante los dos primeros cursos se optó por la localización de varias fotos pero seleccionando un solo documento por alumno en cada colección particular. En el curso 2013-2014 se amplió la selección de dos fotos de media por alumno, y en 2014-2015 se solicitaron cuatro fotos por alumno. La participación total ha sido de 244 alumnos que han aportado cerca de 800 fotografías de las que quedaron 707 tras la selección de las mismas. El descarte de imágenes fue debido a la falta de calidad (desenfoque, fotos movidas, etc.) y en algunos casos al estado de las mismas (Tabla II).

\begin{tabular}{llcc}
\hline Año & Asignatura & Alumnos & Fotografías \\
\hline $2012-2013$ & Documentación fotográfica A & 31 & 31 \\
\hline $2013-2014$ & Documentación fotográfica A & 32 & 63 \\
\hline $2014-2015$ & Documentación fotográfica A & 43 & 344 \\
\hline & Total & 106 & 438 \\
\hline $2012-2013$ & Documentación fotográfica B & 24 & 24 \\
\hline $2013-2014$ & Documentación fotográfica B & 13 & 50 \\
\hline $2014-2015$ & Documentación fotográfica B & 26 & 104 \\
\hline & Total & 63 & 178 \\
\hline $2012-2013$ & Documentación informativa & 30 & 30 \\
\hline $2013-2014$ & Documentación informativa & 25 & 30 \\
\hline $2014-2015$ & Documentación informativa & 20 & 31 \\
\hline & Total & 75 & 91 \\
\hline
\end{tabular}

Tabla II. Asignaturas y fotografías seleccionadas

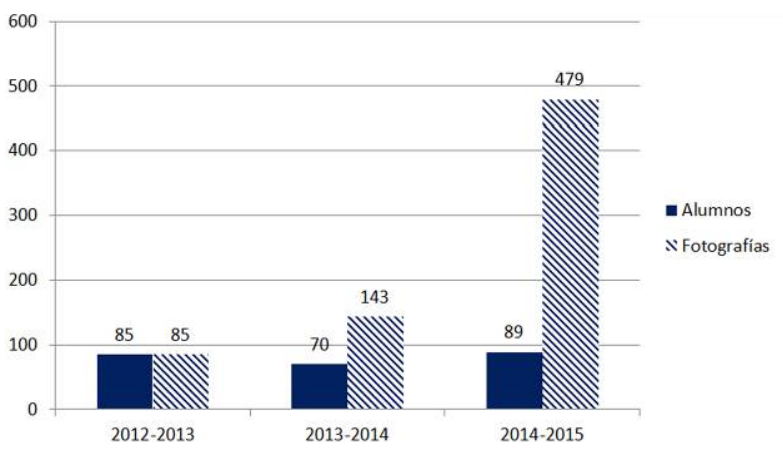

Figura 2. Alumnos y fotografías por curso

La respuesta en el último curso superó la cantidad solicitada, con una media final de 5,3 imágenes por alumno. En consecuencia, el trabajo de documentación aumentó considerablemente, con una excelente respuesta global de la que resultó una gran variedad temática. En el primer año participaron 85 alumnos que aportaron el mismo número de fotos, en el segundo fueron 70 los estudiantes, pero el número de fotos subió a 143 y en el tercer curso de aplicación se consiguieron 479 fotos de 89 alumnos (Figura 2).

\subsection{Docencia, investigación y difusión}

Los resultados docentes pueden considerarse excelentes por la alta participación, por la interacción entre los alumnos, por la comprensión de los contenidos y por el aprendizaje. Tras el desarrollo de las actividades, los estudiantes quedan capacitados para responder a situaciones similares.

a) Resultados docentes

- Participación activa de los alumnos

- Implicación en el proceso selectivo

- Valoración de contenidos 
- Desarrollo de procesos cognitivos

- Trabajo individual y de grupo

- Interacción constante con el profesor

- Aprendizaje de lectura de las imágenes

- Difusión de contenidos

b) Resultados sobre la asignatura: documentación fotográfica

- Creación de un banco de imágenes histórico

- Elaboración de un diccionario de autores de las fotografías

- Listado de palabras clave o temáticas generales

\section{- Aportación de documentos inéditos}

- Nueva metodología para el desarrollo de la asignatura

Una vez efectuado el análisis, tras la elaboración del listado de palabras clave, se agruparon en temas generales, resultando la siguiente estructura a modo de tesauro: Deporte, Educación, Ejército, Familia, Fiestas religiosas, Geografía, Guerra Civil, Música, Retratos, Tradiciones y costumbres, Transporte y Varia. En este último grupo se incluyen las fotos con temáticas diversas, o bien aquellas que son únicas y de las que no se abre nuevo apartado hasta que aumentan en número.

Por lo que respeta a la difusión, esta tarea despierta gran interés y sin embargo en principio no es la más atractiva. Se trata de diseñar una exposición o muestra, presencial o en línea, en la que se difundan los contenidos de la fototeca. En este proceso se elaboran pies de foto informativos y literarios que obligan a incidir en la investigación para obtener la máxima información. En la muestra final se procura la representación de todo el alumnado y de todas las temáticas de las imágenes

\section{Conclusiones}

El proyecto de innovación docente que hemos denominado Fotohistoria incide en la reivindicación del uso de la fotografía en los procesos educativos. Los valores artísticos, informativos y documentales de las imágenes permiten trabajar en numerosos campos y por tanto su aplicación a todas las disciplinas. En el caso que nos ocupa, el desarrollo del proyecto ha alcanzado los dos objetivos generales propuestos: el aprendizaje desde la participación de los estudiantes, y la creación de la fototeca histórica.
Los nuevos métodos docentes son necesarios para contribuir al desarrollo de los programas de Innovación, y a la consecución de los objetivos generales y específicos del Espacio Europeo de Educación Superior, sobre todo en los aspectos referidos a la motivación, participación e interacción de los alumnos. Con esta experiencia, desarrollada en un periodo de tres años, se ofrece un modelo metodológico de trabajo perfectamente aplicable a todo tipo de asignaturas, especialmente en las áreas de ciencias sociales y humanidades.

Los resultados del proyecto (244 participantes con 707 fotos de alta calidad seleccionadas entre cerca de 800) demuestran que se ha fomentado la participación en el aula y fuera de la misma, al realizar trabajos individuales y de grupo para consensuar sobre los contenidos, así como la interacción entre los estudiantes y los coordinadores. Por otra parte, se ha conseguido poner en valor las fotografías como documentos para el estudio de la historia, con aportaciones desde lo particular hacia lo universal, abundando en el estudio e investigación desde la intrahistoria.

Por último, señalaremos que con este proyecto se pone a disposición de la comunidad científica (profesores, investigadores y estudiantes) un banco de imágenes de alta calidad preparado para su uso y aplicación a cuanta actividades y publicaciones se realicen. Todas las fotografías están disponibles en la Fototeca histórica creada al efecto, libres de derechos de autor para uso no comercial, y forman parte del conjunto fotográfico digital de la Universidad Complutense de Madrid.

\section{Referencias}

Britsch, Susan (2010). Photo Booklets for English Language Learning: Incorporating Visual Communication into Early Childhood Teacher Preparation. // Early Childhood Education Journal. 38:3, 171-177.

Casajús, Concha; Diéguez, Silvia; Pena, Carmen (2008). EI arte reproducido. Fotografías de la colección Lafuente Ferrari. Madrid: Edición de las autoras.

García Marco, Francisco Javier (2013). Educación y aprendizaje de la información y la Documentación. // El Profesional de la Información. 22:6 (2013), 489-504.

Heras, Beatriz de las (2012). El testimonio de las imágenes. Fotografía e historia. Madrid: Creaciones Vincent Gabrielle.

López del Ramo, Joaquín (2008). Calidad e Innovación Docente en el Marco de la Convergencia Europea. Madrid: Dykinson.

Marzal, Javier (2008). Cómo se lee una fotografía. Madrid: Cátedra.

Moreiro, José Antonio (2014). Archivos institucionales y docencia sobre imágenes en la Universidad Carlos III de Madrid. // Olivera Zaldua, M.; Salvador Benítez, A. (Eds). Actas del I Congreso de Documentación Fotográ- 
fica. XXIII Jornadas Fadoc. Madrid: Facultad de Ciencias de la Documentación de la UCM, 211-226.

Munakata, Mika; Vaidya, Ashwin (2012). Encouraging Creativity in Mathematics and Science through Photography. // Teaching Mathematics and Its Applications: An International Journal of the IMA. 31:3, 121-132.

Rincón García, Wifredo (2012). Una colección de fotografías de Guillermo Kalho cedida en 1933 por el gobierno de México al profesor Ángulo Íñiguez para sus trabajos de Arte Mexicano. // Rincón García, Wifredo; Pascual Chenel, Álvaro (ed.). Argentum, Estudios artísticos en homenaje a Dra. Amelia López-Yarto Elizalde. Zaragoza: Aneto, 101-118.

Sánchez Vigil, Juan Miguel (editor) (2012). Imaginando: uso y aplicación de la fotografía en los procesos de aprendizaje. Madrid: Universidad Complutense de Madrid.

Sánchez Vigil, Juan Miguel; Marcos Recio, Juan Carlos; Olivera Zaldua, María (2014a). Tesis doctorales sobre

\section{Apéndice: Fotografías cursos 2012-2015}

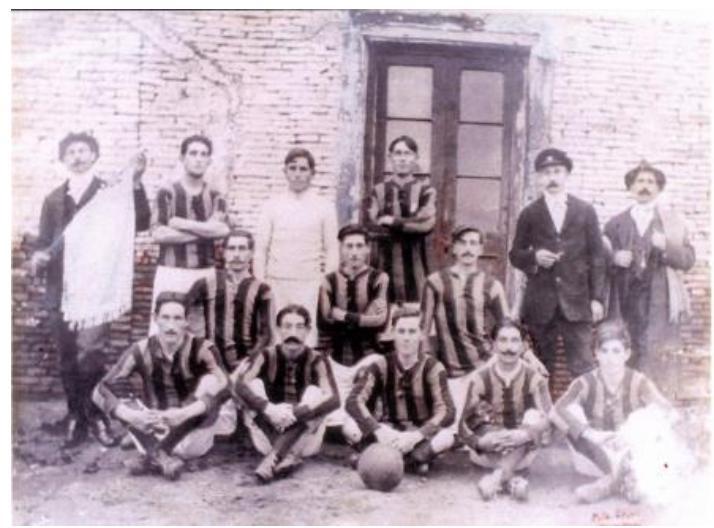

Equipo del Club Atlético Castilla en el pueblo argentino de Castilla, 1920. Foto de autor desconocido. Colección Adolfo Bergerot

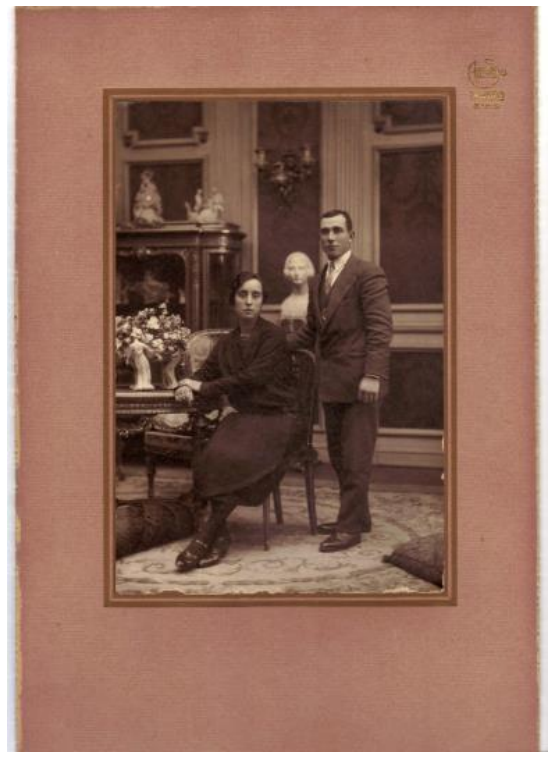

Alfonso García de la Torre y Petronila Montes en el estudio Alfonso de la calle Fuencarral de Madrid, 1928. Colección Rodrigo Sorando García fotografía en la universidad: Análisis de la producción y dirección (1976-2012). // Revista Española de Documentación Científica. 37:1. http://redc.revistas.csic.es/index. php/redc/article/viewFile/837/1075 (2015-03-27)

Sánchez Vigil, Juan Miguel; Marcos Recio, Juan Carlos; Olivera Zaldua, María (2014b). Modelos para el uso de la fotografía en la docencia: el proyecto Imaginando // Ibersid. 8, 33-43.

Sánchez Vigil, Juan Miguel; Salvador Benítez, Antonia (2013). Documentación fotográfica. Barcelona: Universitat Oberta de Catalunya.

Sprinborg, Martin (2013). Teaching and Learning: Visualizing Our Work. // Thought \& Action. 29, 141-149.

Enviado: 2015-03-28. Segunda versión: 2015-05-09. Aceptado: 2013-05-22.

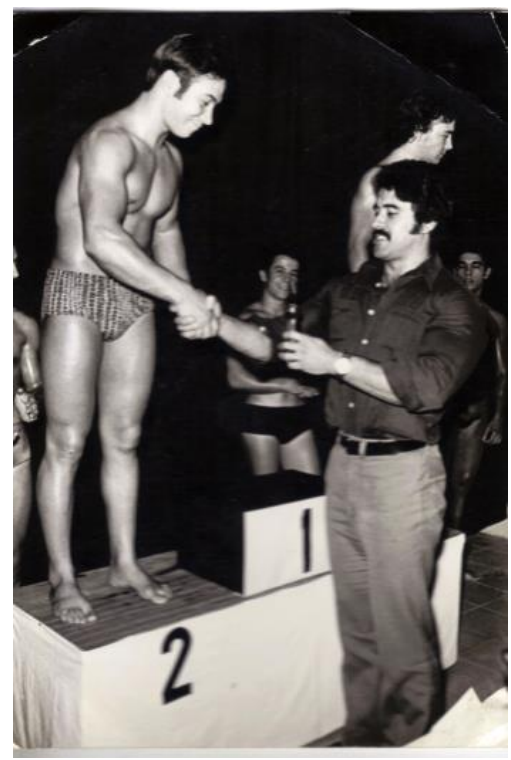

José Carlos Marín recibe el segundo premio del Campeonato de culturismo de Madrid, 1974. Foto de autor desconocido. Colección Silvia Llorente

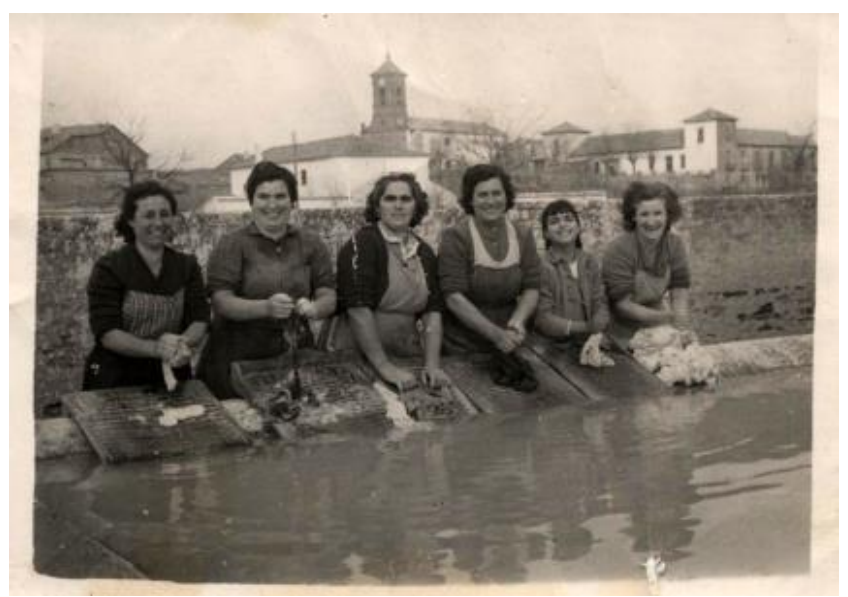

Lavadero de Valdeavero (Madrid), 1950. Foto: Emiliano Sanz. Colección Marta Molés 


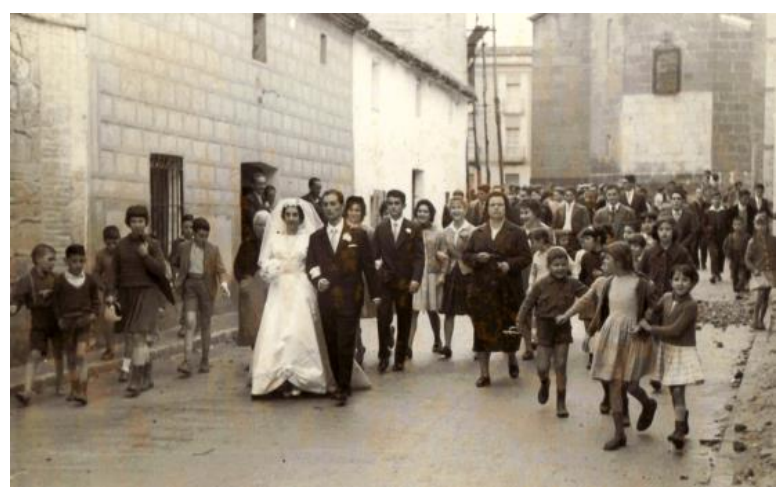

Boda de Eulalia Navas García y Florencio Hinojosa Martín en los Navalmorales (Toledo), 27 de octubre de 1960. Foto: Bastanchuri. Colección Noemí Díaz

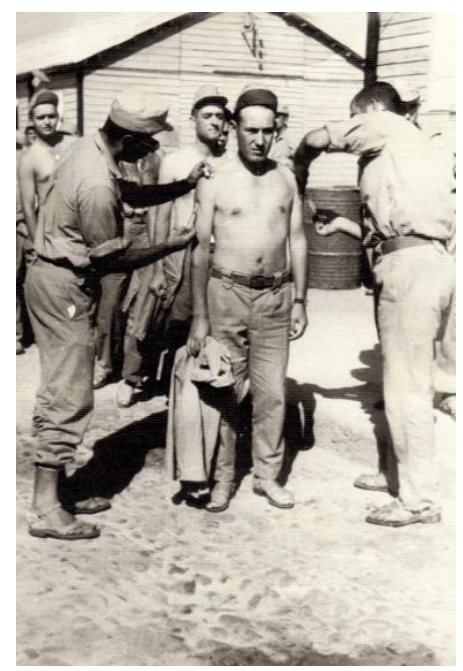

Manuel Gómez vacunado por dos enfermeros militares en Cabeza de Playa (El Aaiún), octubre de 1969. Foto de autor desconocido. Colección Vanesa Gómez

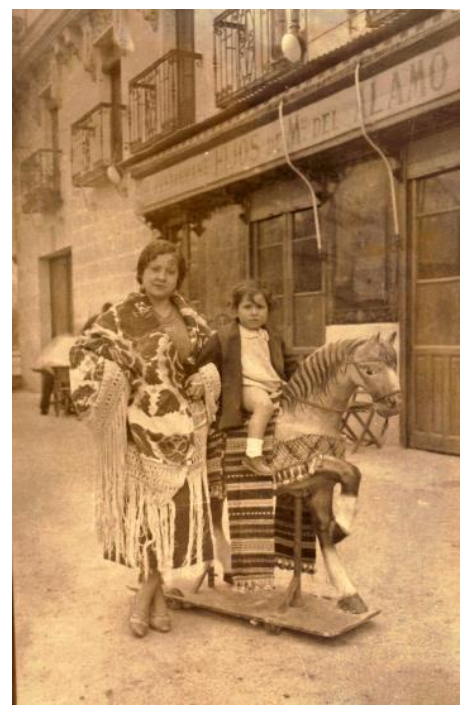

Teresa Jamillo y su sobrina Paloma sentada en un caballo de madera. Madrid, 1940. Foto: Luis Jiménez. Colección Luis Jiménez

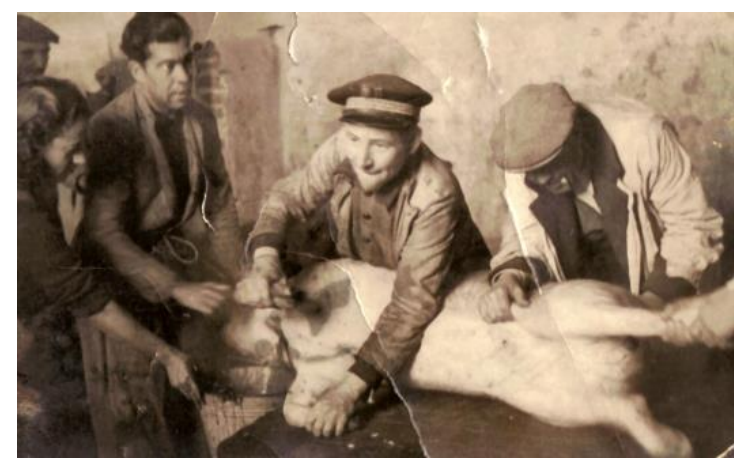

Nono y sus vecinos durante la matanza en Dehesa de Guadix (Granada), h. 1950. Foto de autor desconocido. Colección Óscar Alonso

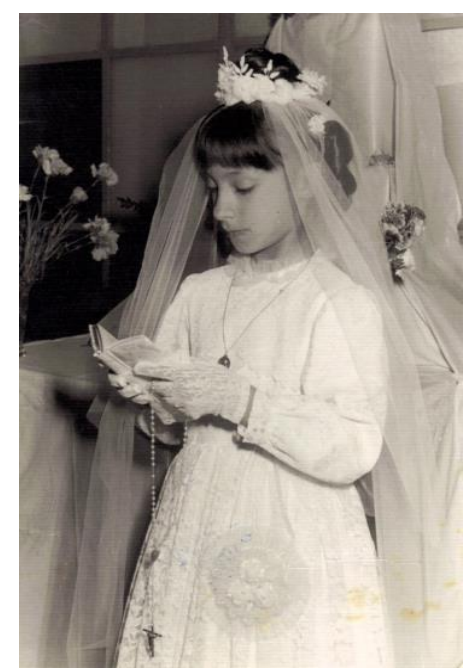

Primera comunión de Teresa Jaramillo en Madrid, 10 de mayo de 1955. Foto de autor desconocido. Colección Daniel Nicolás

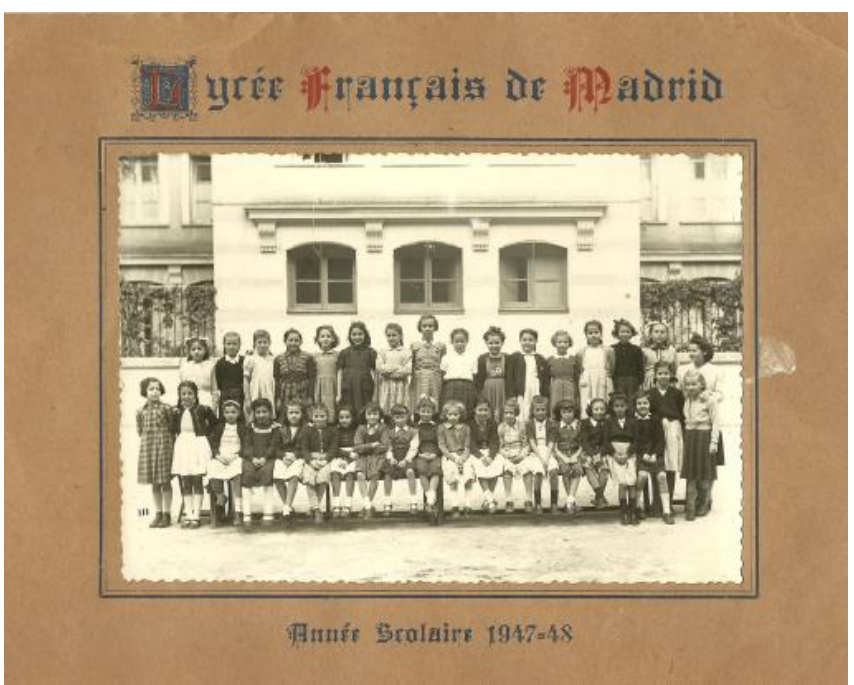

Alumnas del curso 1947-1948 del Liceo Francés de Madrid. Foto de autor desconocido, Colección Igor de la Horra 


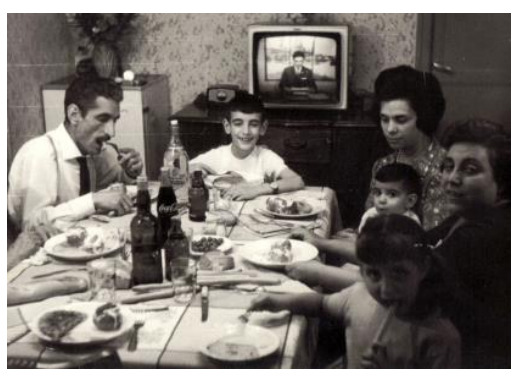

Comida de celebración de la familia Castejón en Madrid, 1965. Foto de autor desconocido. Colección Ana Castejón

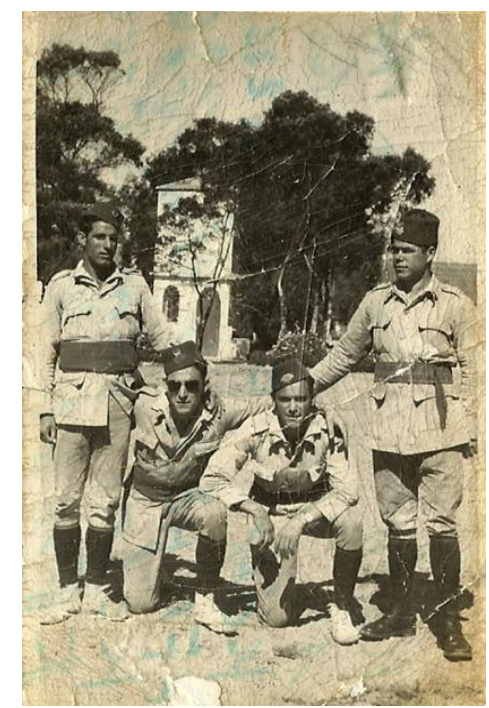

Militares en Melilla, 1947. Foto de autor desconocido. Colección Miguel Osorio 